\title{
Comorbidity and metabolic syndrome in patients with multiple sclerosis from Asturias and Catalonia, Spain
}

\author{
Antoni Sicras-Mainar ${ }^{1}$, Elena Ruíz-Beato ${ }^{2}$, Ruth Navarro-Artieda ${ }^{3}$ and Jorge Maurino ${ }^{4 *}$
}

\begin{abstract}
Background: The impact of comorbidity on multiple sclerosis (MS) is a new area of interest. Limited data on the risk factors of metabolic syndrome (MetS) is currently available. The aim of this study was to estimate the presence of comorbid conditions and MetS in a sample of adult patients with MS.

Methods: A retrospective, cohort study was conducted using electronic medical records from 19 primary care centres in Catalonia and Asturias, Spain. The number of chronic diseases (diagnoses), the Charlson Comorbidity Index and the individual Case-mix Index were used to assess general comorbidity variables. MetS was defined using the National Cholesterol Education Program Adult Treatment Panel III. Patients were distributed into two groups according to the Expanded Disability Status Scale (EDSS) score: 0-3.5 and 4-10.

Results: A total of 222 patients were studied (mean age $=45.5$ (SD 12.5) years, 64.4\% were female and 62.2\% presented a diagnosis of relapsing-remitting MS). Mean EDSS score was 3.2 (SD 2.0). Depression (32.4\%), dyslipidaemia (31.1\%), hypertension (23.0\%) and obesity (22.5\%) were the most common comorbidities. Overall MetS prevalence was $31.1 \%$ (95\% Cl: 25.0-37.2\%). Patients with an EDSS $\geq 4.0$ showed a significantly higher number of comorbidities (OR=2.2; 95\% Cl: 1.7-3.0; $\mathrm{p}<0.001$ ).

Conclusion: MS patients had a high prevalence of MetS. Screening for comorbidity should be part of standard MS care. Further studies are necessary to confirm this association and the underlying mechanisms of MS and its comorbidities.
\end{abstract}

Keywords: Comorbidity, Metabolic syndrome, Multiple sclerosis, Electronic medical records

\section{Background}

Multiple Sclerosis (MS) is a chronic autoimmune disease that affects the central nervous system and has a high impact on the health-related quality of life of patients, their families and society [1,2]. It is one of the most common causes of neurological disability in young adults and its prevalence is increasing throughout Europe [3]. Different epidemiological studies suggest that the prevalence of MS in Spain is also increasing [4,5]. A recent article from the Malaga province in Spain found a prevalence of 125 cases/100,000 inhabitants (95\% CI: 102-169) [6].

\footnotetext{
* Correspondence: jorge.maurino@roche.com

${ }^{4}$ Medical Department, Roche Farma S.A., Madrid, Spain

Full list of author information is available at the end of the article
}

Comorbidity is common in patients who suffer chronic disease; including individuals suffering from MS [7]. The association of comorbidity with health-related quality of life and disability progression has resulted in comorbidity being an area of increasing importance in MS research [2, 8, 9]. Rates of mortality and comorbidities have been shown to be higher in MS patients compared to non-MS patients. A recent observational study of the United States Department of Defence administrative claims database showed that MS patients (vs. a non-MS cohort) had an increased risk of developing a broad spectrum of comorbidity such as sepsis, ischemic stroke, suicide ideation, ulcerative colitis, and cancer (lymphoproliferative disorders and melanoma) [10]. Furthermore, overall risk of postmenopausal breast cancer was 13\% higher amongst MS patients according to the 
Swedish Cancer Registry (HR [95\% CI] $=1.13$ [1.021.26]) [11]. Recent evidence suggests that patients with MS and $\geq 1$ comorbidities have a two-fold increased risk of non-MS-related hospitalisation compared to patients without comorbidity [12].

The metabolic syndrome (MetS) is a global publichealth challenge and a complex disorder characterised by a cluster of interconnected factors which lead to an increased risk of cardiovascular disease (CVD) and diabetes mellitus type 2 [13]. Previous research has shown that for individuals with autoimmune diseases, such as rheumatoid arthritis and systemic lupus erythematosus, the prevalence of MetS is higher than national averages [14]. However, only limited and inconsistent data on MetS risk factors exists for patients with MS [15]. Therefore, the aim of this study was to analyse the presence of comorbidity in a population of patients with MS with especial emphasis on MetS and its individual components.

\section{Methods}

A retrospective, cohort study using electronic medical records from two regions of Spain (Catalonia and Asturias) was conducted. The study analysed patients from 19 primary care centres covering a population of 315,658 inhabitants in a predominantly industrial urban setting with a medium-low socioeconomic status. The study protocol was approved by the investigational review board of the Fundació Unió Catalana d'Hospitals (Barcelona, Spain).

The study included all outpatients who required care in 2015 and fulfilled the following criteria: age $\geq 18$ years; a diagnosis of MS according to the International Classification of Primary Care (IPC-2, code N86) and the International Statistical Classification of Diseases (ICD-9, ninth revision, code 340); inclusion in the long-term prescriptions program (with a record of daily dose, time interval and duration of each treatment administered); and a guaranteed regular patient follow-up (presenting $\geq 2$ healthcare records in the computer system) $[16,17]$. McDonald 2010 criteria were not used in the study because our healthcare database collected diagnosis following only IPC-2 and ICD-9 classifications.

\section{Variables and measurements instruments}

The Expanded Disability Status Scale (EDSS) was used to assess disability [18]. For the purposes of this study, disability was defined as mild to moderate (EDSS score 0$3.5)$ or severe (4.0-10.0). The number of chronic diseases (diagnoses), the Charlson Comorbidity Index and the individual Case-mix Index (obtained from the Adjusted Clinical Groups [ACG] - a classification system based on the consumption of healthcare resources) were used to summarise general comorbidity variables for each patient [19, 20]. The ACG application provides resource utilization bands (RUBs), so each patient was included in one of the five mutually exclusive categories depending on overall morbidity (1: healthy or very low morbidity, 2 : low morbidity, 3: moderate morbidity, 4: high morbidity, and 5: very high morbidity).

The clinical, biochemical and anthropometric parameters analysed were: systolic and diastolic blood pressure $(\mathrm{mm} \mathrm{Hg})$, body mass index (BMI, $\left.\mathrm{kg} / \mathrm{m}^{2}\right)$, basal blood glucose $(\mathrm{mg} / \mathrm{dl})$, serum triglycerides $(\mathrm{mg} / \mathrm{dl})$, total cholesterol (mg/dl), high-density lipoprotein (HDL) cholesterol (mg/ $\mathrm{dl})$; low-density lipoprotein (LDL) cholesterol (mg/dl) and serum creatinine $(\mathrm{mg} / \mathrm{dl})$. The diagnosis of MetS was established when an individual had three or more components of the National Cholesterol Education Program Adult Treatment Panel III (NCEP-ATP III) diagnostic criteria: hypertriglyceridemia (fasting triglyceride concentration $\geq 150 \mathrm{mg} / \mathrm{dl}$ or treatment with triglyceride-lowering agents), dyslipidaemia (fasting HDL- cholesterol $<40 \mathrm{mg} /$ $\mathrm{dl}$ in males and $<50 \mathrm{mg} / \mathrm{dl}$ in females), hypertension (systolic and diastolic blood pressure $\geq 130 / 85 \mathrm{mmHg}$ or on antihypertensive medication), hyperglycaemia (fasting plasma glucose concentration of $\geq 110 \mathrm{mg} / \mathrm{dl}$ or on glucose-lowering drug treatment or a previous diagnosis of diabetes), and abdominal obesity (waist circumference $>102 \mathrm{~cm}$ in males and $>88 \mathrm{~cm}$ in females) [21]. In this study, the waist circumference measurement was replaced by BMI; a BMI $\geq 28.8 \mathrm{~kg} / \mathrm{m}^{2}$ was considered to be equivalent to abdominal adiposity [22].

\section{Statistical analysis}

A descriptive analysis was performed for all variables of interest with mean values, standard deviation (SD) and percentages. The variables were analysed for the overall sample of valid patients and for stratified subgroups according to the EDSS scale score. The Chi-Square and Student's t-tests compared variables by EDSS division. In logistic regression, odds ratios (OR) were adjusted for age, gender, comorbidity (Charlson Comorbidity Index, RUBs) and EDSS score. The SPSSWIN version 19 was used for all analyses. A $p<0.05$ was considered statistically significant.

\section{Results}

Amongst 299,875 subjects aged $\geq 18$ years who required medical care, 225 patients presented a diagnosis of MS and 222 were analysed (Fig. 1).

Socio-demographic and clinical characteristics of the patients are shown in Table 1 . The mean \pm SD age was $45.5 \pm 12.5$ years and $64.4 \%$ were female; $62.2 \%$ of the patients presented a diagnosis of relapsing-remitting MS (RRMS). The mean \pm SD EDSS score was $3.2 \pm 2.0$. Intramuscular interferon beta-1a (30.6\%), subcutaneous interferon beta-1a (23.9\%) and glatiramer acetate $(18 \%)$ were the most common disease-modifying treatments 
Table 1 Socio-demographic characteristics of the sample

\begin{tabular}{|c|c|c|c|c|}
\hline & $\begin{array}{l}\text { EDSS } \\
0-3.5 \\
n=152\end{array}$ & $\begin{array}{l}\text { EDSS } \\
4.0-10 \\
n=70 \\
\end{array}$ & $\begin{array}{l}\text { Total } \\
n=222\end{array}$ & $p$-value \\
\hline Mean age, years (SD) & $42.5(11.5)$ & $52.2(12.2)$ & $45.5(12.5)$ & $<0.001$ \\
\hline Gender, female, \% & 68.4 & 65.7 & 64.4 & 0.292 \\
\hline Mean time since diagnosis, years (SD) & $10.5(7.6)$ & $19.8(10.2)$ & $13.4(9.5)$ & $<0.001$ \\
\hline \multicolumn{5}{|l|}{ MS type, \% } \\
\hline RRMS & 74.3 & 35.7 & 62.2 & $<0.001$ \\
\hline SPMS & 13.8 & 50.0 & 25.2 & $<0.001$ \\
\hline PPMS & 7.2 & 14.3 & 9.5 & 0.094 \\
\hline $\mathrm{ClS}$ & 4.6 & 0.0 & 3.2 & 0.001 \\
\hline \multicolumn{5}{|l|}{ Overall comorbidity, mean (SD) } \\
\hline Number of comorbidities & $4.5(2.7)$ & $6.0(3.3)$ & $5.0(3.0)$ & 0.001 \\
\hline Charlson Index & $0.7(0.6)$ & $1.0(0.7)$ & $0.8(0.6)$ & 0.005 \\
\hline RUBs & $2.9(0.8)$ & $3.2(0.7)$ & $3.0(0.8)$ & 0.003 \\
\hline \multicolumn{5}{|l|}{ Comorbid diagnoses, $\%$} \\
\hline Depression & 34.2 & 28.6 & 32.4 & 0.404 \\
\hline Dyslipidaemia & 25.7 & 42.9 & 31.1 & 0.010 \\
\hline Hypertension & 17.8 & 34.3 & 23.0 & 0.007 \\
\hline Obesity & 22.4 & 22.9 & 22.5 & 0.935 \\
\hline Active smoking & 16.4 & 12.9 & 15.3 & 0.490 \\
\hline Neoplasm & 9.2 & 15.7 & 11.3 & 0.154 \\
\hline COPD & 6.6 & 14.3 & 9.0 & 0.062 \\
\hline Diabetes mellitus & 6.6 & 10.0 & 7.7 & 0.373 \\
\hline Asthma & 7.9 & 2.9 & 6.3 & 0.151 \\
\hline Ischemic stroke & 4.6 & 8.6 & 5.9 & 0.242 \\
\hline Alcoholism & 3.9 & 5.7 & 4.5 & 0.555 \\
\hline Ischemic cardiomyopathy & 2.6 & 8.6 & 4.5 & 0.047 \\
\hline
\end{tabular}

CIS Clinically Isolated Syndrome; COPD Chronic Obstructive Pulmonary Disease; EDSS Expanded Disability Status Scale; MS Multiple Sclerosis; PPMS Primary Progressive MS; RRMS Relapsing-Remitting MS; RUBs Resource Utilization Bands; SD Standard Deviation; SPMS Secondary Progressive MS

administered. A total of 48 patients $(21.8 \%)$ were not receiving immunomodulatory treatment.

Depression (32.4\%), dyslipidaemia (31.1\%), hypertension $(23.0 \%)$, and obesity $(22.5 \%)$ were the most frequent comorbidities (Table 1). The impact of comorbidity was significantly greater in the severe disability group than in group of mild/moderate impairment group: mean number of comorbidities (severe vs. mild/moderate: 6.0 vs. 4.5; $p=0.001)$, Charlson index (1.0 vs. $0.7 ; p=0.005)$, and RUBs (3.2 vs. $2.9 ; p=0.003$ ) (Table 1 ).

Table 2 shows the prevalence of the main cardiovascular risk factors and metabolic syndrome. The overall prevalence of MetS was 31.1\% (95\% CI: 25.0-37.2\%). No statistically significant differences in the MetS prevalence and the number of its components between patients with an EDSS score $<4.0$ vs. $\geq 4.0$ were found. All biochemical and anthropometric parameters were similar between groups. The overall prevalence of cardiovascular risk factors was $14.4 \%$ without statistically significant differences between patients with an EDSS score $\geq 4.0$ (12.0\%) and <4.0 (15.7), $p=0.658$. Furthermore, patients with an EDSS $\geq 4.0$ showed a significantly higher number of comorbidities (RUBs, $\mathrm{OR}=2.2 ; 95 \% \mathrm{CI}: 1.7-3.0 ; p<0.001)$ and longer time to diagnosis $(\mathrm{OR}=1.2 ; 95 \% \mathrm{CI}: 1.1-1.3 ; p=0.023)$.

\section{Discussion}

Comorbidity is associated with diagnostic delays, more severe disability at diagnosis, greater disability progression, cognitive impairment, increased healthcare use, and higher mortality [23]. A systematic review analysed 249 articles indicated that depression, anxiety, hypertension, hypercholesterolemia and chronic lung disease were five of the most prevalent comorbidities in MS patients, whereas thyroid disease and psoriasis were the most common autoimmune diseases [24]. 
Table 2 Prevalence of the main cardiovascular risk factors and metabolic syndrome

\begin{tabular}{|c|c|c|c|c|}
\hline & $\begin{array}{l}\text { EDSS } 0-3.5 \\
n=152\end{array}$ & $\begin{array}{l}\text { EDSS } 4.0-10 \\
n=70\end{array}$ & $\begin{array}{l}\text { Total } \\
n=222\end{array}$ & $p$-value \\
\hline MetS prevalence, $\%$ & 28.9 & 35.7 & 31.1 & 0.311 \\
\hline \multicolumn{5}{|l|}{ MetS components, \% } \\
\hline $\mathrm{BMI}>28.8 \mathrm{~kg} / \mathrm{m}^{2}$ & 30.9 & 30.0 & 30.6 & 0.890 \\
\hline $\begin{array}{l}\mathrm{BP}>130 / 85 \mathrm{mmHg} \\
\text { (or treatment) }\end{array}$ & 30.8 & 40.0 & 33.7 & 0.199 \\
\hline $\begin{array}{l}\text { Triglycerides }>150 \mathrm{mg} / \mathrm{dL} \\
\text { (or treatment) }\end{array}$ & 14.5 & 22.9 & 17.1 & 0.123 \\
\hline Fasting blood glucose $>110$ mg/dL & 11.7 & 10.0 & 11.2 & 0.772 \\
\hline $\mathrm{HDL}-\mathrm{c}<40$ (men) or $<50$ (women) mg/dL & 36.8 & 42.9 & 38.7 & 0.393 \\
\hline Number of components, SD & $1.4(1,3)$ & $1.7(1,5)$ & $1.5(1,4)$ & 0.265 \\
\hline \multicolumn{5}{|l|}{ Total } \\
\hline 1 & 28.9 & 24.3 & 27.5 & 0.532 \\
\hline 2 & 11.2 & 10.0 & 10.8 & 0.822 \\
\hline 3 & 23.0 & 22.9 & 23.0 & 0.758 \\
\hline 4 & 5.3 & 10.0 & 6.8 & 0.163 \\
\hline 5 & 0.7 & 2.9 & 1.4 & 0.234 \\
\hline \multicolumn{5}{|l|}{ Cardiovascular risk factors, mean (SD) } \\
\hline Systolic BP, mmHg & $127.3(14.8)$ & $127.9(15.9)$ & $127.6(15.5)$ & 0.870 \\
\hline Diastolic BP, mmHg & $74.5(10.1)$ & $76.2(9.9)$ & $75.4(10.0)$ & 0.726 \\
\hline $\mathrm{BMl}, \mathrm{kg} / \mathrm{m}^{2}$ & $25.9(4.5)$ & $26.1(4.6)$ & $26.0(4.5)$ & 0.949 \\
\hline Glucose, mg/dL & $93.2(17.6)$ & $93(19.1)$ & $93.1(18.1)$ & 0.985 \\
\hline $\mathrm{HbA} 1 \mathrm{c}, \%$ & 5.8 & 5.8 & 5.8 & 0.255 \\
\hline Triglycerides, mg/dL & $105.7(50.0)$ & $115.1(49.4)$ & $108.7(49.9)$ & 0.545 \\
\hline Total cholesterol, mg/dL & $198.4(38.0)$ & $202.2(41.5)$ & $199.6(39.1)$ & 0.691 \\
\hline LDL-C, mg/dL & $119.5(36.5)$ & $124.1(39.6)$ & $121.0(37.4)$ & 0.458 \\
\hline $\mathrm{HDL}-\mathrm{C}, \mathrm{mg} / \mathrm{dL}$ & $59.2(17.5)$ & $60.3(17.2)$ & $59.5(17.4)$ & 0.366 \\
\hline Serum creatinine, mg/dL & $1.1(0.1)$ & $1.1(0.1)$ & $1.1(0.1)$ & 0.888 \\
\hline High cardiovascular risk, \% & 12.0 & 15.7 & 14.4 & 0.658 \\
\hline
\end{tabular}

BP Blood Pressure; BMI Body Mass Index; EDSS Expanded Disability Status Scale; HbA1c Glycated Haemoglobin; HDL-C high-density lipoprotein cholesterol; LDL-C low-density lipoprotein cholesterol; MetS Metabolic Syndrome; SD Standard Deviation

Our analysis of 222 MS patients from two different regions of Spain provides support for the presence of comorbidities and MetS in MS patients, as well as a trend for increasing comorbidity with increasing MS disability. Depression, dyslipidaemia, hypertension, and obesity were the most frequently observed comorbidities. Furthermore, a 31.1\% prevalence of MetS was found.

The ENRICA study showed a MetS prevalence of $22.7 \%$ (95\% CI: $21.7-23.7 \%$ ) in a sample of 11,143 adult subjects in Spain [25]. Information about MetS in MS is still very scarce [15]. However the results of our study agree with previous research. Similarly, Pinhas-Hamiel et al. found a MetS prevalence of $30 \%$ with no gender difference in a sample of 130 MS patients with significant disability (EDSS score $\geq 3$ ) [26].

In a systematic review analysing 34 studies, Wens et al. found an increased CVD risk in MS patients compared to healthy controls [15]. Lalmohamed et al. showed a 3.5fold increased mortality rate in MS compared with the general population, which was mainly caused by increased deaths due to CVD (2.4-fold) [27]. However, it is not clear whether this increased risk of CVD is related to obesity or changes in body composition, dyslipidaemia, hypertension or type II diabetes [15]. Many symptoms of MS such as mobility disability and fatigue could increase the prevalence of sedentary behaviour and may have considerable implications for the development of cardiovascular comorbidities [28]. In this context, physical exercise may be a feasible intervention targeting the CVD risk.

Our study has several limitations inherent to research based on population databases, such as the presence of missing values or diagnostic codification differences [29]. In addition, socioeconomic levels, lifestyle factors 
and concomitant medications were not evaluated as factors associated with CVD risk.

\section{Conclusions}

In recent years there has been a big change in the management of MS. Treatment decisions are becoming more complex due to the introduction of several new diseasemodifying treatments with a more diverse spectrum of risks and benefits [30]. Before starting a treatment, neurologists should carefully consider the state of the disease, its prognostic factors and comorbidities, response to previous treatments, and patient preferences [31, 32]. Comorbidity screening should be part of standard MS care [33]. The findings in this study may help to establish an expectation of comorbidities, identify high-risk patients, educate MS patients in preventive measures and facilitate decisionmaking in clinical practice [33, 34]. Further studies need to be undertaken in order to validate these finding, and to gain a better understanding of the underlying mechanisms of MS and its comorbidities.

\section{Abbreviations}

ACG: Adjusted clinical groups; BMl: Body mass index; BP: Blood pressure; CIS: Clinically isolated syndrome; COPD: Chronic obstructive pulmonary disease; CVD: Cardiovascular disease; EDSS: Expanded disability status scale; HbA1c: Glycated haemoglobin; HDL: High-density lipoprotein; HR: Hazard ratio; ICD-9: International statistical classification of diseases; IPC-

2: International classification of primary care; LDL: Low-density lipoprotein; MetS: Metabolic syndrome; MS: Multiple sclerosis; NCEP-ATP III: National cholesterol education program adult treatment panel III; OR: Odd ratio; PPMS: Primary progressive multiple sclerosis; RRMS: Relapsing-remitting multiple sclerosis; RUBs: Resource utilization bands; SD: Standard deviation; SPMS: Secondary progressive multiple sclerosis
\end{abstract}

\section{Acknowledgements}

None.

\section{Funding}

The study was funded by Roche Farma SA, Spain.

\section{Availability of data and materials}

The dataset of the current study is available from the corresponding author on reasonable request.

\section{Authors' contributions}

ASM, ERB, RNA and JM developed the research question. ASM designed the study, wrote the protocol and performed the statistical analyses. All authors contributed to and have approved the final manuscript.

\section{Ethics approval and consent to participate}

The study protocol was approved by the investigational review board of the Fundació Unió Catalana d'Hospitals (Barcelona, Spain).

\section{Consent for publication}

Not applicable.

\section{Competing interests}

ERB and JM are employees of Roche Farma SA. None of the other authors report any conflict of interest.

\section{Publisher's Note}

Springer Nature remains neutral with regard to jurisdictional claims in published maps and institutional affiliations.

\section{Author details}

'Fundación Rediss (Red de Investigación en servicios Sanitarios), Barcelona, Spain. ${ }^{2}$ Health Economics and Outcomes Research Unit, Roche Farma S.A., Madrid, Spain. ${ }^{3}$ Department of Medical Information, Hospital Universitari Germans Trias i Pujol, Badalona, Barcelona, Spain. ${ }^{4}$ Medical Department, Roche Farma S.A., Madrid, Spain.

Received: 15 March 2017 Accepted: 9 July 2017

Published online: 17 July 2017

\section{References}

1. Ayuso Gl. Multiple sclerosis: socioeconomic effects and impact on quality of life. Med Clin (Barc). 2014;143(Suppl 3):7-12.

2. Berrigan LI, Fisk JD, Patten SB, Tremlett H, Wolfson C, Warren S, Fiest KM, McKay KA, Marrie RA; CIHR Team in the Epidemiology and Impact of Comorbidity on Multiple Sclerosis (ECOMS). Health-related quality of life in multiple sclerosis: Direct and indirect effects of comorbidity. Neurology. 2016. [Epub ahead of print].

3. Howard J, Trevick S, Younger DS. Epidemiology of multiple sclerosis. Neurol Clin. 2016;34:919-39.

4. Otero-Romero S, Roura P, Solà J, Altimiras J, Sastre-Garriga J, Nos C, Vaqué J, Montalban X. Increase in the prevalence of multiple sclerosis over a 17-year period in Osona, Catalonia. Spain Mult Scler. 2013;19:245-8.

5. Candeliere-Merlicco A, Valero-Delgado F, Martínez-Vidal S, Lastres-Arias MDC, Aparicio-Castro E, Toledo-Romero F, Villaverde-González R. Prevalence of multiple sclerosis in Health District III, Murcia. Spain Mult Scler Relat Disord. 2016;9:31-5.

6. Fernández O, Fernández V, Guerrero M, León A, López-Madrona JC, Alonso A, Bustamante R, Tamayo JA, Romero F, Bravo M, Luque G, García L, Sanchís G, San Roman C, Romero M, Papais-Alvarenga M, de Ramon E. Multiple sclerosis prevalence in Malaga, southern Spain estimated by the capturerecapture method. Mult Scler. 2012;18:372-6.

7. Estruch BC. Cormorbidity in multiple sclerosis and its therapeutic approach. Med Clín (Barc). 2014;143(Suppl 3):13-8.

8. Marrie RA, Rudick R, Horwitz R, Cutter G, Tyry T, Campagnolo D, Vollmer T. Vascular comorbidity is associated with more rapid disability progression in multiple sclerosis. Neurology. 2010;74:1041-7.

9. Culpepper WJ. The incidence and prevalence of comorbidity in multiple sclerosis. Mult Scler. 2015;21:261-2.

10. Capkun G, Dahlke F, Lahoz R, Nordstrom B, Tilson HH, Cutter G, Bischof D, Moore A, Simeone J, Fraeman K, Bancken F, Geissbühler Y, Wagner M, Cohan S. Mortality and comorbidities in patients with multiple sclerosis compared with a population without multiple sclerosis: an observational study using the US Department of defense administrative claims database. Mult Scler Relat Disord. 2015:4:546-54.

11. Hajiebrahimi M, Montgomery S, Burkill S, Bahmanyar S. Risk of premenopausal and postmenopausal breast cancer among multiple sclerosis patients. PLoS One. 2016;11:e0165027.

12. Marrie RA, Elliott L, Marriott J, Cossoy M, Tennakoon A, Yu N. Comorbidity increases the risk of hospitalizations in multiple sclerosis. Neurology. 2015; 84:350-8.

13. Kassi E, Pervanidou P, Kaltsas G, Chrousos G. Metabolic syndrome; definitions and controversies. BMC Med. 2011;9:48.

14. Versini $M$, Jeandel PY, Rosenthal E, Shoenfeld $Y$. Obesity in autoimmune diseases: not a passive bystander. Autoimmun Rev. 2014:13:981-1000.

15. Wens I, Dalgas U, Stenager E, Eijnde BO. Risk factors related to cardiovascular diseases and the metabolic syndrome in multiple sclerosis - a systematic review. Mult Scler. 2013;19:1556-64.

16. Lamberts $\mathrm{H}$, Wood M, Hofmans-Okkes I. The international classification of primary Care in the European Community. With a multi-language layer. Second edition. Oxford: Oxford University Press; 1993.

17. World Health Organization. Ninth Revision, International Classification of Diseases (ICD-9). Geneva, 1999

18. Kurtzke JF. Rating neurologic impairment in multiple sclerosis: an expanded disability status scale (EDSS). Neurology. 1983;33:1444-52.

19. Charlson ME, Pompei $P$, Ales KL, MacKenzie CR. A new method of classifying prognostic comorbidity in longitudinal studies: development and validation. J Chronic Dis. 1987:40:373-83.

20. Weiner JP, Starfield BH, Steinwachs DM, Mumford LM. Development and. application of a population-oriented measure of ambulatory care case-mix. Med Care. 1991;29:452-72. 
21. National Cholesterol Education Program Expert Panel on Detection, Evaluation, and Treatment on High Blood Cholesterol in Adults (Adult Treatment Panel III). Third report of the National Cholesterol Education Program (NCEP) Expert Panel on Detection, Evaluation, and Treatment of High Blood Cholesterol in Adults (Adult Treatment Panel III) final report. Circulation. 2002;106:3143-421.

22. Sattar N, Gaw A, Scherbakova O, Ford I, O'Reilly DS, Haffner SM, Isles C, Macfarlane PW, Packard CJ, Cobbe SM, Shepherd J. Metabolic syndrome with and without C-reactive protein as a predictor of coronary heart disease and diabetes in the west of Scotland coronary prevention study. Circulation. 2003:108:414-9.

23. Marrie RA. Comorbidity in multiple sclerosis. Some answers, more questions. Int J MS. 2016;18:271-2.

24. Marrie RA, Cohen J, Stuve O, Trojano M, Sorensen PS, Reingold S, Cutter G, Reider N. A systematic review of the incidence and prevalence of comorbidity in multiple sclerosis: overview. Mult Scler. 2015;21:263-81.

25. Guallar-Castillón P, Pérez RF, López García E, León-Muñoz LM, Aguilera MT, Graciani A, Gutiérrez-Fisac JL, Banegas JR, Rodríguez-Artalejo F. Magnitude and management of metabolic syndrome in Spain in 2008-2010: the ENRICA study. Rev Esp Cardiol. 2014;67:367-73.

26. Pinhas-Hamiel O, Livne M, Harari G, Achiron A. Prevalence of overweight, obesity and metabolic syndrome components in multiple sclerosis patients with significant disability. Eur J Neurol. 2015;22:1275-9.

27. Lalmohamed A, Bazelier MT, Van Staa TP, Uitdehaag BM, Leufkens HG, De Boer A, De Vries F. Causes of death in patients with multiple sclerosis and matched referent subjects: a population-based cohort study. Eur I Neurol. 2012;19:1007-14.

28. Veldhuijzen van Zanten JJ, Pilutti LA, Duda JL, Motl RW. Sedentary behaviour in people with multiple sclerosis: Is it time to stand up against MS? Mult Scler. 2016;22:1250-6.

29. Motheral B, Brooks J, Clark MA, Crown WH, Davey P, Hutchins D, Martins BC, Stanq P. A checklist for retrospective database studies-report of the ISPOR task force on retrospective databases. Value Health. 2003;6:90-7.

30. Comi G, Radaelli M, Soelberg SP. Evolving concepts in the treatment of relapsing multiple sclerosis. Lancet. 2017;389:1347-56.

31. Brück W, Gold R, Lund BT, Oreja-Guevara C, Prat A, Spencer CM, Steinman L, Tintoré M, Vollmer TL, Weber MS, Weiner LP, Ziemssen T, Zamvil SS. Therapeutic decisions in multiple sclerosis: moving beyond efficacy. JAMA Neurology. 2013;70:1315-24.

32. Arroyo R, Sempere PA, Ruiz-Beato E, Carreño A, Roset M, Maurino J. Conjoint analysis to understand multiple sclerosis patients' preferences for disease-modifying therapy attributes in Spain. BMJ Open. 2017;7:e014433.

33. Marrie RA. Comorbidity in multiple sclerosis: implications for patient care. Nat Rev Neurol. 2017. [Epub ahead of print].

34. Haghikia A, Gold R. Positive effect on multiple sclerosis with treatment of metabolic syndrome. JAMA Neurol. 2016;73:499-500.

\section{Submit your next manuscript to BioMed Central and we will help you at every step:}

- We accept pre-submission inquiries

- Our selector tool helps you to find the most relevant journal

- We provide round the clock customer support

- Convenient online submission

- Thorough peer review

- Inclusion in PubMed and all major indexing services

- Maximum visibility for your research

Submit your manuscript at www.biomedcentral.com/submit
Biomed Central 